Article

\title{
Revisiting the French Didactic Tradition through Technological Lenses
}

\author{
Michèle Artigue ${ }^{1, *}$ and Luc Trouche ${ }^{2}$ (1) \\ 1 Laboratoire de Didactique André Revuz (LDAR), Université de Paris, F-75013 Paris, France \\ 2 French Institute of Education, Ecole Normale Supérieure de Lyon, 69342 Lyon, France; \\ luc.trouche@ens-lyon.fr \\ * Correspondence: michele.artigue@univ-paris-diderot.fr
}

check for

updates

Citation: Artigue, M.; Trouche, L. Revisiting the French Didactic

Tradition through Technological Lenses. Mathematics 2021, 9, 629. https://doi.org/10.3390/math9060629

Academic Editor: Jarmila Novotná

Received: 19 February 2021

Accepted: 11 March 2021

Published: 16 March 2021

Publisher's Note: MDPI stays neutral with regard to jurisdictional claims in published maps and institutional affiliations.

Copyright: (C) 2021 by the authors Licensee MDPI, Basel, Switzerland. This article is an open access article distributed under the terms and conditions of the Creative Commons Attribution (CC BY) license (https:// creativecommons.org/licenses/by/ $4.0 /)$.

\begin{abstract}
There is, in France, a long-term tradition of research in the didactics of mathematics. In this paper, we revisit this tradition using, as a specific lens, the research carried out on the educational use of digital tools and resources for teaching and learning mathematics. We first briefly introduce this tradition and the three main theories at the base of it: the theory of didactical situations, the theory of conceptual fields, and the anthropological theory of the didactic. Then, considering three different technological lenses, i.e., dynamic geometry environments, computer algebra systems, and digital resources, we show how these theories and the long-term connection established in this tradition with the fields of cognitive ergonomics and computer sciences have influenced technological research and its outcomes. We also show that, conversely, didactic technological research has led to original and influential theoretical constructions, such as the instrumental approach and the documentational approach to didactics, and that it has contributed in a substantial way to the opening of this didactic tradition to other didactic cultures and other communities, beyond the didactic one.
\end{abstract}

Keywords: anthropological theory of the didactic; computer algebra system; didactical engineering; didactic technological research; digital resources; documentational approach to didactics; dynamic geometry environment; instrumental approach to didactics; theory of conceptual fields; theory of didactical situations

\section{Introduction}

There is a long-term tradition of research in the didactics of mathematics in France, with characteristics that distinguish it from other didactic traditions, even within continental Europe [1]. The expression Ecole Française de Didactique is regularly used, even though many researchers around the world have contributed and are contributing to this tradition, as shown for example by the texts prepared for the thematic afternoon devoted to the didactic traditions of continental Europe at ICME-13 (International Congress of Mathematics Education) in 2016 [2,3]. We present, in the second section of this article, the main features of this French didactic tradition.

In this article, our aim is to approach this tradition using, as a specific lens, the research carried out on the educational use of digital tools and resources for teaching and learning mathematics. Didactic research in this area, which we refer to in this article as didactic technological research (DTR hereafter), developed quite early in France, driven by favorable institutional conditions such as the rapid inclusion of calculators and mathematics software in curricula and curricular documents, as well as the early acceptance of calculators in national examinations, particularly the baccalauréat, which concludes secondary education and opens access to university. As we shall show, research in this field has been nourished by this didactic tradition and has nourished it in return, leading to original and influential theoretical constructions, such as the instrumental approach [4] and the documentational approach to didactics [5]. This is why we consider it a good lens through which to approach this tradition. 
This lens also allows us to show the importance of interactions with other communities in the development of this tradition, i.e., other didactic communities of course, but also communities outside the didactic field. For DTR, two such communities have been especially influential, that of computer scientists working in the area of EIAO (initially Enseignement Intelligemment Assisté par Ordinateur, and then Environnements Interactifs Assistés par Ordinateur-Interactive Environments Assisted by Computer; this community today uses the acronym EIAH (Environnements Informatiques pour l'Apprentissage humain-Computer Environments for Human Learning)) and that of researchers in cognitive ergonomics. As shown by the special issue of the journal Recherches en Didactique des Mathématiques published in 1994 [6], collaboration with the EIAO community was initiated early and, thanks to it, emblematic projects emerged from the 1980s onward, as for instance the Cabri-géomètre and Aplusix projects presented in [6] and still active today. Connections with the field of cognitive ergonomics also have a long history in the French didactic tradition, not limited to DTR. They were established as early as the 1980s, within the framework of a Didactic Research Group created by the CNRS (Centre National de Recherche Scientifique-National Center for Scientific Research) [7]. We show the essential role this connection played in the development of the instrumental and documentational approaches to didactics.

We address DTR by successively using three different technological lenses: dynamic geometry environments (DGE), calculators and computer algebra systems (CAS), and digital resources. These offer complementary perspectives on this tradition. In the third section, devoted to DGE, we focus on software emblematic of this area whose development began in the 1980s, initially named Cabri-Géomètre and then Cabri in its further versions. This enables us to show the influence on the associated DTR of the Theory of Didactic Situations (TDS) [8], one of the bases of this tradition [2], as well as the role of interactions among didacticians, mathematicians, and computer scientists. In the fourth section, addressing calculators and CAS allows us to look at the French didactic tradition through the development of the instrumental approach that emerged in this context in the mid-1990s, before being extended to other technologies such as spreadsheet, dynamic geometry, and online tutorials and resources. This lens allows us to show the influence of the connection mentioned above with researchers in cognitive ergonomics, as well as the roles played in the development of the instrumental approach by the Theory of Conceptual Fields (TCF) [9] and the Anthropological Theory of the Didactic (ATD) [10], the two other theoretical bases of the French didactic tradition [2]. The extension of the instrumental approach to consider the teacher also makes it possible to point out the role played in DTR and this tradition by more recent theoretical approaches, such as the dual ergonomic and didactic approach to teaching practices initiated by Robert and Rogalski [2,11]. In the fifth section, broadening the perspective, we lastly use the lens of digital resources. With this lens, a new theoretical construction enters the scene: the documentational approach to didactics. It emerged only about 10 years ago in the French didactic tradition, also motivated by technological evolution, and it can be viewed as an extension of the instrumental approach. It has been the source of new and promising connections, likely to enrich this tradition. Lastly, in the final section, we come back to the main ideas developed throughout the article, regarding how the French didactic tradition has influenced the DTR developed within it and contributed to its originality and productivity, as well as how, in return, DTR has contributed and is contributing to the dynamics of this tradition and its openness to other didactic cultures and to other communities as well. We also examine the potential and limitations of this particular lens to approach this tradition.

\section{The French Didactic Tradition: Some Important Characteristics}

Before using the three lenses described in the introduction, we now briefly introduce this tradition and some of its important characteristics. A first characteristic is the central place given to mathematics itself and its epistemology. This characteristic, as shown by research in the history of education (see, for example, [12]), has its origins in the historical involvement of mathematicians in educational matters, a commitment which was already 
evident at the time of the French Revolution and which has continued up to the present day, particularly thanks to the existence of the IREM network (Institut de Recherche sur l'Enseignement des Mathématiques-Research Institute on Mathematics Teaching) created in the context of the New Math reform. As explained in [2,13], in these university institutes close to mathematics departments, mathematicians, didacticians, teachers, and teacher educators work collaboratively. Didactic research emerged in the IREMs, and, for 50 years now, they have been feeding it with problems and have disseminated its results through the professional development activities they organize for teachers and through their different publications. They also play an essential role in the interaction between theory and practice through the action research projects they carry out. They have enabled didactic research to develop in close interaction between researchers and teachers, as well as in close contact with the reality of classrooms, which is well reflected in the importance given in this tradition to didactic engineering [14].

Another characteristic of this French didactic tradition is that, from its emergence, while building connections with other scientific fields-initially mainly mathematics and psychology, and then many others-it has aimed at constituting the didactics of mathematics as a genuine scientific field, structured by its proper questions, theories, and methodologies. Moreover, in a context marked by the disillusionment caused by the New Math reform, priority has been given to research aimed at understanding the interwoven and complex processes of teaching and learning, as well as the functioning of the didactic systems that shape them, as expressed in the following quotation from Brousseau ([13], p. 228):

"Avant de chercher à influencer l'enseignement, il convient d'abord de l'observer et de le comprendre en n'agissant que de façon limitée, contrôlée a priori par des connaissances scientifiques et a posteriori par des expériences reproductibles.» (Before seeking to influence teaching, it is first necessary to observe and understand it by acting only in a limited way, controlled a priori by scientific knowledge and a posteriori by reproducible experiments (translation by the authors)).

The aim was, thus, to build solid foundations for this new scientific field, both conceptually and methodologically. Conceptually, this tradition was built up around three theories: the TCF and the TDS, due to Vergnaud and Brousseau, respectively, generally considered as the two founding fathers of the French didactics [2,7], and the Theory of Didactic Transposition due to Chevallard [15], later extended by him into the ATD. We cannot go into a detailed presentation of these three theories in this article. In this section, we only provide a brief introduction. It is complemented in the following sections, depending on the issues addressed and the research works mentioned.

The perspective offered by the TCF is of a cognitive and developmental nature, and it is directly inspired by Piaget's cognitive epistemology (Vergnaud was a doctoral student of Piaget) [9]. It takes up and reworks the Piagetian concept of scheme, within a dialectic vision of the interaction between schemes and situations. More precisely, Vergnaud defines a scheme as the invariant organization of action for a class of situations and distinguishes in it four components: goals, subgoals, and anticipations; rules of action; operational invariants (concepts in action or theorems in actions); possibilities of inferences. Vergnaud also introduces the concept of a conceptual field defined as a "set of situations and a set of concepts tied together" ([9], p. 86). Conceptual fields, for example, the additive and multiplicative conceptual fields, which Vergnaud studied extensively, constitute for him the relevant unit for approaching and understanding the processes of conceptualization and learning. He also insists on the distinction that must be made between two forms of knowledge, operational knowledge that makes it possible to act and predicative knowledge that makes it possible to formulate and justify action.

While influenced by Piagetian epistemology and its vision of learning as a process of adaptation, Brousseau's project was different [2]: to found a genuine experimental epistemology of mathematics on the basis of the construction of situations able to make mathematical knowledge emerge from autonomous students' interactions with their environment in the social context of classrooms and from the observation and analysis of classroom implementa- 
tions. The central object here is, therefore, not the cognitive subject, i.e., the pupil or student, but the situations organizing the relationship of such subjects with mathematical knowledge and its raisons d'être. Key constructs are, thus, those of an adidactic situation and milieu. The concept of an adidactic situation models such situations in which students would develop their knowledge autonomously without trying to guess the didactic intention of the teacher. The concept of a milieu models the environment with which they interact and provides them with objective feedback. It may comprise informative texts, material objects, and digital tools, as well as other students, collaborating or competing. The COREM (Centre pour l'Observation et la Recherche sur l'Enseignement des Mathématiques-Center for observation and research on mathematics teaching), created in 1972, and the Michelet primary school attached to it have played a decisive role in the development of this project over 25 years. This role is attested by emblematic works of didactic engineering such as the one associated with the extension of the field of numbers, from whole numbers toward rational and decimal numbers [16]. The key concepts of the TDS emerged and were consolidated thanks to the COREM activities, not only those mentioned above, but also many others. The reader not familiar with this theory can find a detailed introduction to TDS and its main concepts in the AMOR (Awardees Multimedia Online Resources) unit devoted to Guy Brousseau (https://www.mathunion.org/icmi/awards/amor/guy-brousseau-unit/, accessed on 13 March 2021). AMOR is a project launched by the ICMI (International Commission on Mathematical Instruction) to make the influential research of ICMI awardees widely accessible.

With the theory of didactic transposition [15], in the early 1980s, an ecological questioning of the mathematical knowledge taught emerged, focusing on the sources of this knowledge and the successive transformations it undergoes, from the moment the decision is taken to include it in a curriculum to its implementation in classrooms. ATD then broadened the perspective by placing at the center of the analysis the diverse institutions, institutional positions, and institutional relationships with knowledge at stake and how these condition and constrain what is taught and, therefore, what students ultimately have the possibility to learn or not. To this end, new concepts were introduced, notably the concept of praxeology and the scale of didactic codeterminacy. The concept of praxeology is intended to propose a general model of human practices. It is made of a praxis block (a type of task and a technique for solving it) and a logos block (a "technological" (i.e., its ATD etymological meaning of logos on the technique) discourse explaining and justifying the technique, and a more general discourse, a theory, supporting the technological discourse). These blocks are in dialectic interaction, and the concept is used for analyzing both mathematical and didactical practices. The scale of didactic codeterminacy accounts for the different levels of conditions and constraints shaping mathematical and didactical praxeologies, as well as the interactions between these, from those situated at the level of a mathematical question or topic to those resulting from our condition as human beings. It currently comprises 10 levels: topics or questions, themes, sectors, domains, disciplines, pedagogies, schools, societies, civilizations, and humanity. Once again, detailed information can be found in the AMOR unit devoted to Yves Chevallard (https: / / www.mathunion.org/icmi/awards/amor/yves-chevallard-unit/, accessed on 13 March 2021). However schematic, this presentation makes clear that these three theories offer different perspectives for approaching the complexity of teaching and learning processes. Gradually, French didacticians have learned to play productively on their complementarity in their research work, as we show in the upcoming sections. Over the years, research within this tradition has, of course, evolved. The issues addressed have become more diverse, for instance, paying increasing attention to teachers, their preparation and professional development, their practices, and their resources. The diversity of methodologies and theoretical constructions has also increased, but the characteristics outlined above remain at the forefront of this tradition, as does the role played by these three theories, which are themselves constantly being reworked and enriched. As made clear by the survey prepared for ICME-13 [3] and the contributions of researchers from Germany, Italy, Mexico, and Tunisia to the thematic afternoon [2], the French didactic tradition has disseminated 
all over the world, particularly in Europe and in the Francophone space, as well as in Latin America and some Asiatic countries. In return, it has benefitted from these exchanges with other didactic traditions and approaches, in addition to other educational cultures. These have enriched the French tradition as we show in the next sections, and they have also contributed to its opening to problématiques such as multilinguism and ethnomathematics.

\section{A Tradition Seen through the Lens of Dynamic Geometry}

As announced, in this section, we use the lens of research concerning dynamic geometry environments (DGE) to approach the French didactic tradition, particularly research with/about Cabri-géomètre and Cabri [17]. Like any lens, this one is reductive. Even in its beginnings, DTR carried out in France was not limited to geometry. Early on, for instance, in the IREM network, DTR began to develop on the teaching and learning of calculus at high-school and university levels with calculators. In the field of geometry itself, research and development activities were diverse, focusing on the didactic use of the Logo language or of the Euclide software derived from it, on the development of the Geoplan and Geospace software, which have long been used in secondary education, and even on software designed to assist the elaboration of mathematical proofs as was the case for DEFI and MENTONIEZ [6,13]. The Cabri adventure is, however, singular, for its pioneering character (Cabri-Géomètre and Sketchpad were the first two DGEs), its longevity, and its international expansion [17].

Cabri-géomètre was developed by Jean-Marie Laborde, a researcher in theoretical computer science and graph theory at the IMAG (Institut de Mathématiques Appliquées de Grenoble-Institute of Applied Mathematics of Grenoble), from the Cabri software (Cabri standing for "Cahier de Brouillon Informatique" in French, i.e., "Digital Draft Notebook" in English) created for research in graph theory. From the outset, this development has closely associated computer scientists, mathematicians, and didacticians within the IMAG. This DGE was seen as a medium for creating adidactic milieux allowing students to make sense of the idea of a geometric figure, to explore geometrical configurations, conjecture their properties, and test these conjectures through their interactions with it. The TDS concepts of adidactic situation and milieu, already introduced, as well as that of didactic variable, were at the heart of this interaction between didactics and computer science. The didactic variables of a situation are those, in the hands of its designer or user, which are likely to influence the cost and efficiency of solving strategies.

The often-quoted article [18] by Laborde and Capponi is a good illustration. Drawing on existing research in the didactics of geometry, especially the distinction between drawing and geometric figure ("the geometrical figure is a geometrical object described by the text defining it, as an idea, a mental construction, while a drawing is a representation of it." ([18], p. 168) (authors' translation)), which is crucial for the conceptualization of the notion of a geometric figure [19], the authors first show the limits of the paper and pencil environment and of the tasks usually proposed to students to make sense of this distinction. They then make the hypothesis, on the basis of an a priori analysis of Cabri-géomètre, that this software makes it possible to overcome these limitations. Their argument is that Cabri-géomètre offers both drawing commands (creation of a point, a line, or a circle, for example) and geometrical construction commands (constructing the perpendicular to a line passing through a point, for example) and the possibility of invalidating drawings, visually looking satisfactory but not constructed properly, thanks to the dragging command. In appropriate situations, Cabri-géomètre feedback should, thus, allow students to achieve this distinction and to do so in a-didactic mode, i.e., without relying on the teacher's help or judgment.

This requires the design of appropriate situations. The authors describe one example in great detail. In it, students are asked to construct a line parallel to a given line $(D)$ and passing through a point $P$ outside it. In such a situation, the choice of the command allowed is an important didactic variable. Here, the command menus have been drastically reduced (an essential possibility offered by this software). In the "Construction" menu, for instance, the commands "Point on object", "Intersection of two objects", "Symmetric point 
with respect to a line or to a point", and "Angle bisector", only, are accessible. In addition, the line $(D)$ has been created with the "Basic line" command of the "Creation" menu, which makes it possible to create a line passing through a single point. Their motivation is to prevent a blind iteration of the symmetry commands from two points on the line making appear by chance a point perceptually located on the parallel asked for. In their a priori analysis of this situation, the authors explain how these choices were made to create an antagonist adidactic milieu, in the sense of TDS, and what effects they anticipate from these choices. Then, analyzing in detail the students' procedures in two grade 8 classes, which the Session Journal command makes possible, they confirm the potentialities identified in the a priori analysis. The students begin with constructions using drawing commands; for example, they create a basic line passing through $\mathrm{P}$ and perceptually adjust its orientation to make it parallel to $(D)$. These first constructions do not resist dragging; however, thanks to their interaction with the software and their interpretation of perceptual feedback, all students eventually produce, without external help, correct geometrical constructions. The two constructions presented in Figure 1 are the dominant ones. The authors also identify unexpected procedures combining drawing and construction commands, for example, when students create a basic line and turn it to make it perceptually perpendicular to $(D)$, then construct the symmetry of $\mathrm{P}$ with respect to this line, to determine the parallel looked for. The authors also observe that geometry can emerge as a means of reproducing or explaining visual effects, in the face of unexpected visual phenomena produced by their actions, for example, by a combinatorial game with commands of the menu. According to the authors, this opens up a new way, in which "learning geometry in its early stages would consist of learning to control the relationships between the visual and the geometric" (ibid., p. 205, our translation), playing on the dialectic between the visual and the geometric instead of opposing them.

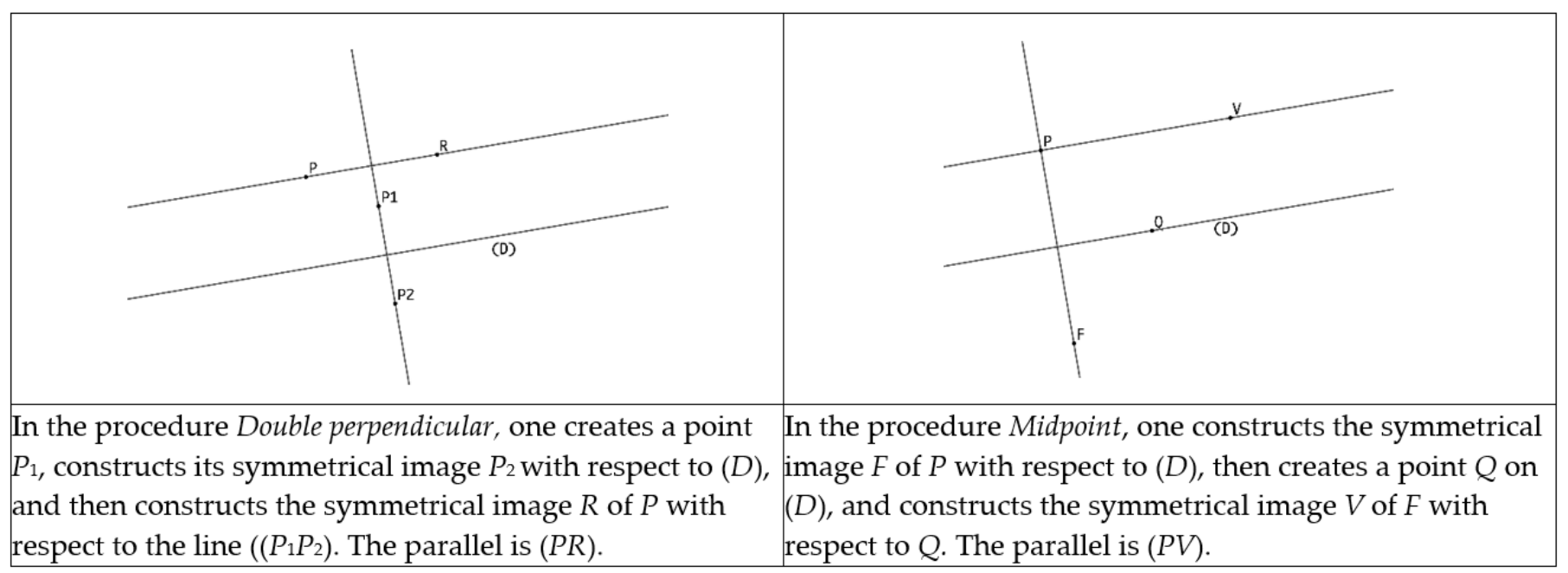

Figure 1. The two predominant correct procedures in the parallel construction task.

Over the following decades, the research and development activities carried out at the IMAG around Cabri-géomètre and then Cabri II, Cabri II Plus, and Cabri 3D have continued to be based on this vision of DGE as a medium for creating adidactic milieus and on the design of didactic engineering supported by TDS. These activities have made clear that the full exploitation of the didactic potential of this software, and more generally of DGE, required the creation of situations without equivalents in the paper-and-pencil environment. The famous "black-box" situations, where students have to discover what is hidden behind a geometric object, construction, or transformation created with the software, are excellent examples. However, teachers do not easily imagine or use such situations when they try to exploit DGE. A long learning process is necessary, as shown for instance by the 3 year project described in [20]. 
The international success encountered by Cabri-géomètre and its successors has also been the source of fruitful collaborations where the TDS has been combined with other theoretical approaches, particularly the semiotic approaches developed by Italian didacticians. The study in [21] is a good example in which TDS was combined with the theory of semiotic mediation to explore the potential offered by Cabri for introducing the concept of function in a co-variational perspective, using a didactic engineering methodology.

These international collaborations have also revealed an underestimated complexity underlying the dragging command. For instance, Healy [22] showed the heuristic power of what she called "soft constructions", fulfilling only part of the requested geometrical constraints. Arzarello and his colleagues [23] distinguished seven different types of dragging: dragging test, wandering dragging, bounded dragging, guided dragging, dummy locus dragging, line dragging, and linked dragging. Researchers also progressively discovered that making sense of dragging is not obvious at all for students. It requires a specific and often long-term learning process, highly dependent on students' geometrical knowledge, especially with regard to the goals assigned to dragging and the interpretation of its effects. This was highlighted by the MAGI project (Mieux Apprendre la Géométrie avec l'InformatiqueBetter Learning Geometry with Software), which started in 2003, focused on the teaching and learning of geometry in primary schools and at the beginning of middle school in France with the software Cabri II Plus [24]. In this project, a new theoretical ingredient was incorporated: the instrumental approach. It helped understand the complexity and take it better into consideration in the design of tasks and their progression, as shown in module 6 of the Artigue unit of the ICMI AMOR project mentioned in Section 2, devoted to the extension of the instrumental approach to dynamic geometry (https: / www.mathunion.org/ icmi/awards/amor/michele-artigue-unit, accessed on 13 March 2021). It is precisely this instrumental approach that we examine in the next section.

\section{A Tradition Seen through the Lens of Calculators and Computer Algebra Systems}

This section proposes a view on the French tradition of research through the lens of calculators and computer algebra systems (CAS). Calculators and CAS constitute indeed different tools, but the technological evolution led them to, in a certain sense, converge toward handheld computing tools. From 1980, calculators became more and more complex, from scientific calculators, to graphic ones, and then to "symbolic" ones, i.e., integrating a CAS [25]; meanwhile some CAS, such as DERIVE [26], were integrated in smaller and smaller platforms. The use, by the students, of these platforms revealed complex phenomena. Their didactical analysis led to the emergence of a new theoretical approach, the instrumental approach to didactics, which we present in the first subsection. This approach developed through bringing together other theoretical frameworks and through applying it to other technological environments. We describe this evolution in the second subsection. After focusing on students' learning, the dynamics of didactical studies led to the teacher being taken into account, under different perspectives; we examine this theoretical evolution in the third subsection.

Calculators were often introduced in classrooms by the students themselves. Students' habit of using calculators (their own property), often without the teacher's monitoring, led to new didactical phenomena (Figure 2), going against optimistic assumptions of tools that would naturally support learning and evidencing the complexity of mathematics learning in complex technological environments. The provision of powerful tools such as CAS, integrating functionalities of graphical representation and of both numerical and formal computation, does not necessarily facilitate conceptualization. Analyzing these phenomena required specific experimental research that was supported by the French Ministry of Education. Several IREMs and laboratories of research mobilized to study the process of integration of CAS and of symbolic calculators in ordinary high-school classrooms [27]. This research drew attention to the influence of images on conceptualization [28] and to a range of phenomena well described by Artigue [2]. She combined, for her analysis, the ATD (for thinking about the social and institutional conditions of technological integration), 
the TDS (for thinking about the design of situations taking advantage of tools), and the computational transposition, introduced by Balacheff [29], for modeling the distance between a mathematical entity and the way it is represented by a tool. This research indicated the need for rethinking the link between the technical and the conceptual dimensions of tasks.

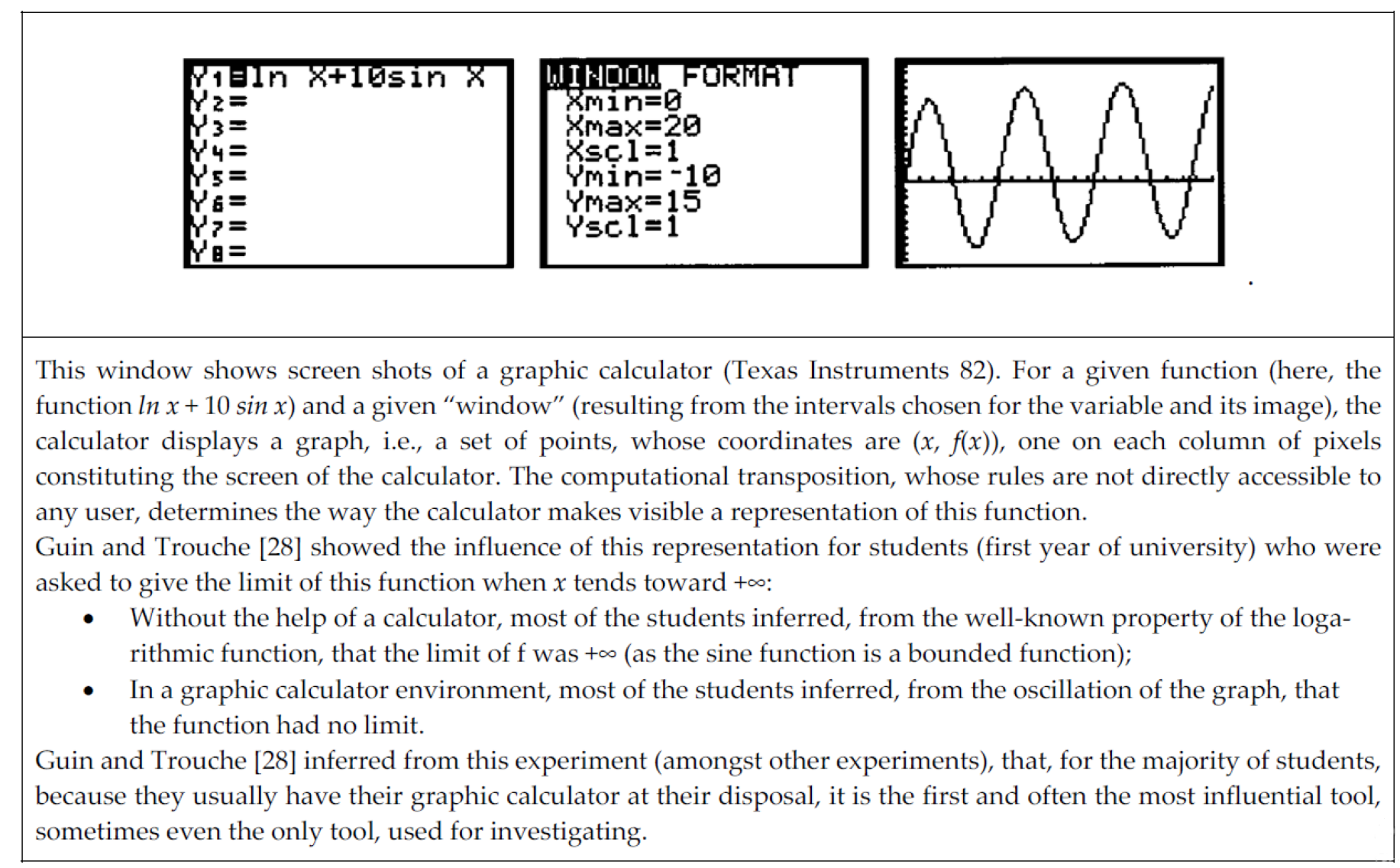

Figure 2. The influence of graphic calculators on mathematical conceptualization.

A posteriori, it appeared that we missed theoretical tools for further questioning this link. The so-called instrumental approach, emerging after 1990 in the field of cognitive ergonomics in France [30] and at an international level [31], made available such tools. Rabardel was a student of Vergnaud, and he retained, for developing this frame, some essential features of the TCF, particularly the duality scheme/class of situations (see Section 2), facilitating its appropriation by the community of didactics of mathematics. This approach is based on a double dialectic:

- An artefact/instrument dialectic: each artefact, defined as a product and means of human activity, is engaged by the subject in the course of their situated activity; the instrument is developed, from this artefact, by the subject. It is defined as a hybrid entity, composed of the part of the artefact actually used and the scheme of use;

- An instrumentation/instrumentalization dialectic: instrumentation is the process by which the use of the artefact influences the activity of the subject; instrumentalization is the process by which the subject adapts/enriches the artefact to make it more efficient and more suited to their needs.

The process of developing an artefact into an instrument, called instrumental genesis, combines instrumentation and instrumentalization.

As soon as it was introduced [32,33], this approach, in line with previous interactions between mathematics didactics and cognitive ergonomics ( $\$ 2)$, spread quite widely in the community of researchers of the domain, giving means for examining the role of calculators 
and CAS for mathematics learning. Using this approach, Defouad's thesis [34] investigated the links between mathematical and technical knowledge during the instrumental genesis; Trouche's thesis [35] investigated the interactions between instrumentation and conceptualization processes. This approach did not develop in isolation, but in symbiosis with the structuring frames of the French didactics, i.e., the TCF of course, but also the ATD, for taking into account the institutional constraints of the instrumental geneses (the case of Defouad's thesis), and the TDS, for thinking about the didactic situations feeding these geneses (the case of Trouche's thesis). This theoretical development was also the occasion to deepen the interactions with the semiotic approach [36] and the EIAH domain [37].

This approach applied also beyond the original domain of CAS, for example, to the domain of dynamic geometry (see the MAGI project mentioned above and [38]) or spreadsheet [39], both technologies integrated in the French curriculum since the end of the 20th century. The fact that DTR, in France, went across the community of didactics of mathematics, more particularly the laboratories more advanced in this domain (Grenoble, Montpellier, and Paris), favored the circulation of the instrumental approach and its extension. The summer school of didactics of mathematics, in 1997, was an important milestone from this point of view, with a topic dedicated to DTR, organized around a lecture of Rabardel [40] presenting the instrumental approach, and two courses, concerning the research on CAS [41] and Dynamic Geometry [42]. A technical reason for the focus on these tools was the fact that symbolic calculators integrated, in addition to a CAS, a spreadsheet and a DGE (e.g., TI-92 from Texas Instruments, integrating Cabri-géomètre), leading to joint research; thus, the European French speaking conference, held in 1998, was the occasion of bringing together the studies concerning the so-called "symbolic and geometric calculators" [43].

From the research organized during this period (1990-2000), thanks to the fertilization of the traditional frameworks of mathematics didactics by the instrumental approach, some major results emerged. Among them, emerged the complexity of instrumental geneses and their specific mathematical needs, the double function, both epistemic and pragmatic, of techniques in learning processes, and the imbalance between these functions generated by the ordinary use of calculators and CAS, the status of instrumented techniques, the problems arising from their connection with paper/pencil techniques, and their institutional management ([44], p. 252). This research also produced a diversity of didactic engineering products likely to help teaching practices benefit from these results. These evolutions were not of course restricted to the French community; the book edited by Guin, Ruthven and Trouche [45], analyzing the process of "turning a computational device into a mathematical instrument", and the book issued from the ICMI study on technology and mathematics education [46] witness the dissemination of this approach at an international level.

The following period (2000-2010) was the site of convergent developments. The literature review (1994-1998) by Lagrange et al. [47] revealed the evolutions underway at the international level at the end of the last century, particularly the critical role of the teacher in supporting the integration of various artefacts in the classroom. Beyond just DTR, this interest in the teacher appears clearly in the French community of mathematics didactics, through the reflection on the teacher's figure [48], the analysis of their activity [49], or the double approach, didactic and ergonomic, of teacher practices [11]. This last approach, based on Activity Theory, expresses, as does the instrumental approach, the productivity of interactions between the communities of cognitive ergonomics and mathematics didactics. In this approach, teachers' practices are seen as coherent and stable objects that can be described through five components: cognitive, mediative, societal, institutional, and personal. The cognitive and mediative components regard the organization of tasks and the teacher-student interactions in their implementation, respectively. They are the main components. The three others correspond to different types of determinations of these two components.

The technological integration processes are then conceived in a double dimension, with the teachers appropriating artefacts for themselves and supporting their appropriation by the students. The awareness of this duality led to different conceptualizations: 
- That of instrumental orchestrations, defined by Trouche [50] and further developed in a joint work with Drijvers [51] as "the systematic arrangement by an intentional agent of the elements (artefacts and humans) of an environment in order to implement a didactical situation", taking up the notion of "didactical exploitation scenario" already introduced by Chevallard [48];

- That of double didactic and mathematical genesis [52], expressing the fact that, for a teacher and a given digital artefact, two instrumental geneses take place, the first one transforming it into a mathematical instrument and the second one transforming it into a didactical instrument;

- That of genesis of technology uses by teachers [53], taking account of the fact that the teacher's activity combines the use of diverse artefacts, digital or not, as well as the fact, in line with the double approach mentioned above, that the analysis of teachers' instrumented practices cannot be isolated from a more global approach to their practices.

These conceptualizations emerged in the thread of different DTR projects, e.g., the Ile-de-France region project, dedicated to the use by mathematics teachers and students of online resources [54], the SFoDEM project, dedicated to teacher education for, and, in using technologies [55], and the GUPTEn project [56] dedicated to the study of teachers' professional geneses of technologies. These projects are emblematic of the development of the Internet and of the usage, by the students, as well as by the teachers, of online resources. They announce the development of theoretical frameworks to come, focusing on the notion of resources, our next lens. Sokhna's thesis [57], dedicated to the instrumental geneses of pedagogical resources, is part of this movement.

Throughout this lens of calculators and CAS, we see more directly at work (compared to the previous lens of DGE), the contributions of the TCF and the ATD, two distant theories but yet productively combined by researchers, once some tensions were overcome. For instance, researchers had to clarify the relationships between schemes (in TCF) and techniques (in ATD), which generated many discussions (see, for instance, [58] and [59]). From this lens, we also see more clearly the place taken by research on teacher professional development in DTR, and a connection with this research was undoubtedly facilitated by the links constituted in this period between the fields of cognitive ergonomics and didactics, through both the instrumental approach and the double approach.

\section{A Tradition Seen through the Lens of Digital Resources}

This section proposes another view on the French tradition of research through the lens of digital resources and the Internet. We first examine the emergence, in the thread of the instrumental approach, of a new theoretical approach, the so-called documentational approach to didactics (DAD); then, we present some further developments, both methodological and theoretical; last, we underline some conditions which have favored such developments.

The development of the Internet resulted in the profusion of online resources and the development of new forms of communication. It led to new phenomena, among them the emergence of online teachers' associations, designing and sharing, at a very large scale, teaching resources (the French Sésamath association (https:/ /www.sesamath.net/, accessed on 13 March 2021) appearing emblematic of this evolution; see [60]). This led to a question of how to rethink, under these conditions, teacher professional development.

As explained in [61], conceptual advances came from encounters with different theoretical proposals. Jill Adler's proposition [62] to think of a resource as everything that re-sources or that has the potential to re-source the teacher's activity undoubtedly played a decisive role (the fact that the wordplay around "re-sourcing" can be understood in both English and French languages was also indeed important). The EIAH community [63] helped also to conceptualize the notion of resources interrelated with the notion of learning environment, as well as the Pedauque pluridisciplinary network [64], gathering computer scientists, psychologists, sociologists, and information architects proposing the notion 
of document as something bearing an intention and both informing and resulting from a socially situated human activity. It led, in the conceptualization to come (see below), the choice of the word "document" for naming the result of the teachers' interactions with resources during their activity for facing a class of situations.

Conceptual advances came also from the internal dynamics of the community of mathematics didactics. As in the case of the instrumental approach, a summer school of mathematics didactics, that of 2007, helped to crystallize a first model. One of its themes was devoted to studying the following question: "What is a document in mathematics education?" The work on this theme was structured by three contributions. The first came, as in 1999, from the cognitive ergonomics community; Viviane Folcher [65] proposed a reflection on "Design for use, design in use: which resources for which activities?" The two other contributions came from mathematics didactics: Gueudet and Trouche [66], conceptualizing mathematics teachers document systems, and Margolinas and Wozniak [67], analyzing the place of documents in the development of mathematics education. The Folcher and Gueudet-Trouche contributions were situated in the thread of the instrumental approach, while Margolinas and Wozniak combined the ATD and TDS frameworks. The different contributions share the same sensitivity to institutional constraints and collective aspects, to the diversity of times and places of teacher work, and to the long-term of resource development.

Gueudet and Trouche proposed the emerging DAD model, which, fundamentally, substitutes the resource-document dialectics to the artefact-instrument dialectics proposed by the instrumental approach. The DAD model retains essential traces of the instrumental approach model, particularly the instrumentation-instrumentalization dialectics, and the notion of genesis, but analyzes teachers' activity through the lens of their interactions with resources. Throughout the course of teachers' situated activity, fed by the resources they use/design, documentational geneses develop and result in documents; these are hybrid entities made of resources updated/recombined and of schemes of usage. Each document comprises a mathematical and a didactical component, strongly intertwined.

Gueudet and Trouche [68] illustrate this approach through the case of a teacher addressing the situation "introducing the formula for area of a parallelogram for grade 7" (the paperboard extract in Figure 3 corresponds to that situation; during the previous session, the teacher proposed to her students a task that would provide evidence for this formula). She drew on a set of resources for this situation and developed a document. Two aspects of the data indicate here a regularity:

- For many different mathematical contents, she prepared lesson frames comprising texts with empty slots, particularly when a new formula is presented;

- She reported that she had taught the same lesson for 3 years, using word processing software, several websites, the digital textbook, the interactive whiteboard, and a paper form to be filled in by students.

The material aspect of the document resulting from this genesis is a file prepared for the whiteboard and a paper sheet to be filled in by each student. Its mathematical component comprises the area formula and the computation of areas in several cases. Its didactical component lies in the organization of a classroom discussion allowing the teacher to write the missing elements of the formula on the whiteboard, while the students do the same on their paper form and then apply the formula in direct application exercises (Figure 3) and finally in more complicated cases. We can infer, not only from one lesson, but from the regularity of this teacher's work when facing the same class of situations, some components of the corresponding scheme: action rules, such as "propose a text with empty slots" (general rules) or "propose different positions of the parallelogram and of the heights" (specific rules), and operational invariants, such as "students understand and memorize better a formula when a class discussion is organized before the teacher writes the formula on the board" (general operational invariants) or "the side-horizontal and height-vertical associations must be avoided" (specific operational invariants). 


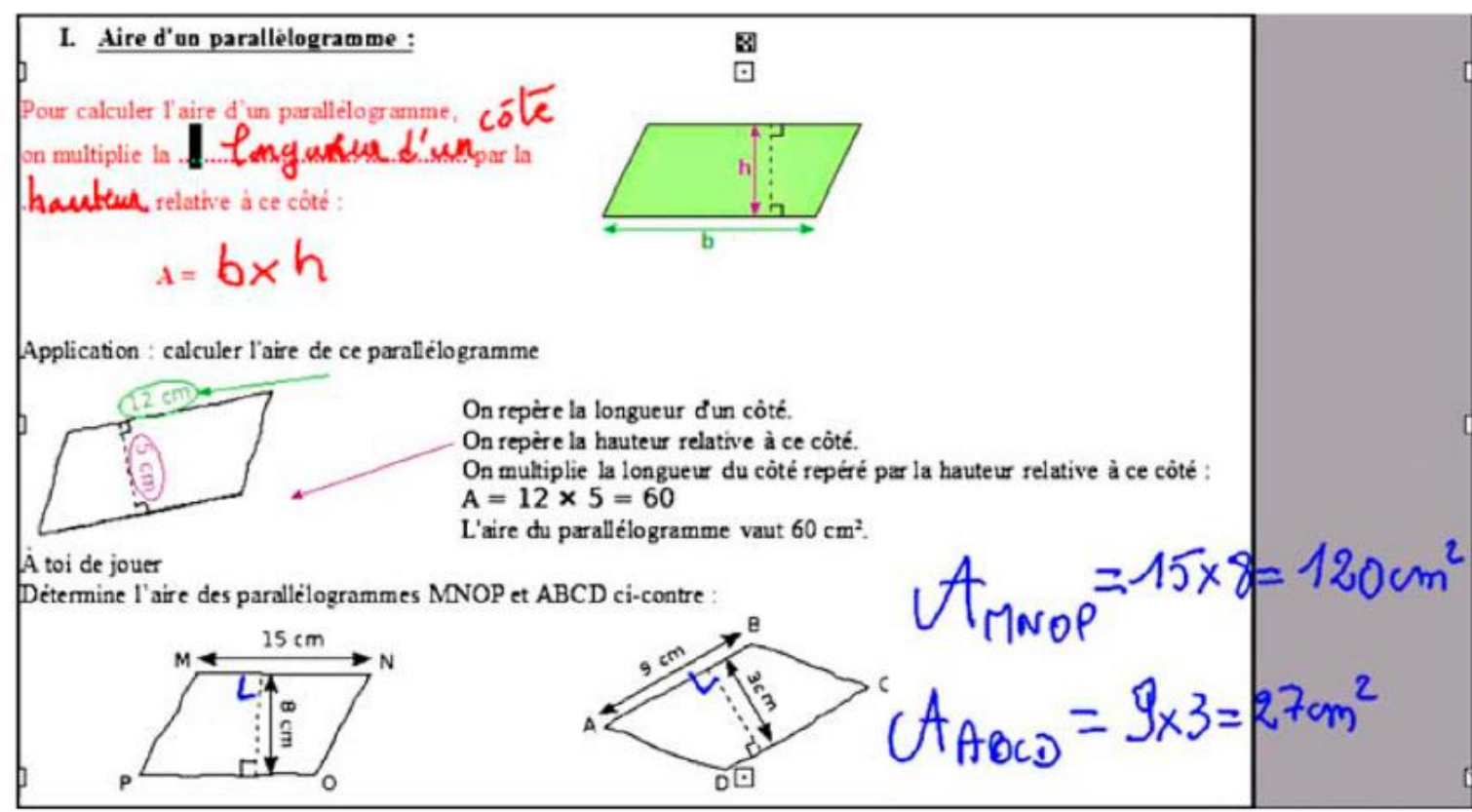

Translation of the screen: 1 . Area of a parallelogram.

To calculate the area of a parallelogram, we multiply the length of one side by the associated height.

Application: calculate the area of this parallelogram.

We identify the length of one side.

We identify the corresponding height.

We multiply the length of the side by the height: $\mathrm{A}=12 \times 5=60$.

The area of the parallelogram is $60 \mathrm{~cm}^{2}$.

Your turn to play. Find the area of the parallelograms MNOP and ABCD below.

Figure 3. Traces, on an interactive whiteboard, of a teacher's work introducing the computation of the area of a parallelogram ([68], p. 208).

The instrumental and documentational models seem, thus, to be close (see [69] for a contrasting view), but they nevertheless differ practically on three essential points:

- The DAD develops a holistic point of view on the teacher's work, embracing not only some predominant artefacts, but all the resources in this work: material and symbolic; coming from Internet, as well as from the interactions with colleagues or students; resources already "there" or collected for addressing a new issue. These views lead to the productive notion of resource system embracing the diversity of resources a teacher interacts with;

- It recognizes as essential the process of instrumentalization, considering that adopting a resource is always adapting it (whereas it was not, at the beginning at least, the case in the instrumental approach, as the adaptation of environments such as CAS was not so obvious). In the documentational approach, the processes of usage and design appear as intrinsically linked, as announced by the seminal lecture by Folcher [65];

- Lastly, the DAD is interested in "ordinary" classes, trying to take into account, as much as possible, the institutional conditions constraining teacher activity.

The needs, which arose from applying this approach to a diversity of contexts, led to methodological and theoretical improvements.

The methodological improvements resulted from the need to follow teachers' interactions with resources, termed teachers' documentation work, over quite a long period of time, in each place where this work occurred (in classrooms, as well at home, or when 
meeting colleagues informally). The need for having access, as much as possible, to teacher documentation work led to the development of a "reflective investigation methodology", giving a major role to the teacher's involvement in the data collection strategy. Various methodological tools were developed in this perspective (see [70] for a retrospective analysis), such as logbooks, teachers' mapping of their resource systems, or protocols for following up teachers over a given mathematics topic.

The theoretical improvements are of course linked to the methodological ones, occurring particularly throughout different PhD studies, e.g., Sabra's work [71], leading to a deepening of the methodological contract to be developed between a teacher and a researcher aiming to understand her documentation work, Hammoud's work [72], leading to distinguishing between mother resources, feeding teacher documentation work, and daughter resources, resulting from teacher documentation work, or Rocha's work [73], modeling teacher professional development in terms of the notion of teacher's documentational trajectory. It should be noted that, throughout the development of DAD, the collective aspect of teacher work, present from the emergence of the approach [74], took a bigger and bigger place [75], due to new forms of teachers' interactions entailed by the development of the Internet.

Four main conditions have made these theoretical and methodological improvements possible:

- The connection still alive with the three main frameworks grounding the French didactics (the dialectic scheme/situation from the TCF, the institutional constraints of teacher work from the ATD, and the analysis of task design for TDS);

- The application of DAD in various institutional contexts, from primary schools [76] to higher education [69];

- The application of DAD in various cultural contexts beyond the French one, for example, in China [77], making it possible to deepen the conditions of teachers collective work;

- The interaction with other traditions of research, for example, with Ruthven [78] for deepening the notion of resource system, with the field of research on textbooks [79], for better understanding the critical role of "traditional" resources, or, more generally, with the field of research on curricular resources [80], for taking into account the institutional conditions of teacher documentation work.

These developments appear clearly from the first edited book presenting DAD [81], mostly based on French contributions to the second one [82] bringing together other international traditions of research focusing on teacher-resource interactions. One of the characteristics of DAD has been the emergence of an international community of research, thanks particularly to PhD studies in the French speaking area, in Latin America, in Europe, and in Asia. The Re(s) source 2018 International Conference, held in Lyon in 2018 [83], gathering participants from 33 countries, demonstrated such an emergence.

Of course, further developments are needed to address the complexity of teacherresource interactions, extending the DAD toward a broader "Resource" approach to mathematics education [84]. The perspective of deepening the analysis of these interactions in contrasting traditions of research, languages, and cultures seems to be promising [85].

\section{Discussion}

In this article, we approached the French tradition in didactics of mathematics, through the lens of DTR.

This tradition has been nurtured and has fed in return the conceptualizations at work in the international community of mathematics education, as evidenced in two key conferences organized by the International Commission on Mathematics Instruction dedicated to technologies. The first one was held in Strasbourg 1985, aiming to study The influence of computers and informatics on mathematics and its teaching [86], and the second one in Hanoi 2006, aiming to study Mathematics education and technologies-Rethinking the terrain [46]. The evolution of their titles is emblematic of the dynamics of the field that we 
described in this paper. The same evolution appears in the titles of the journals of the field, e.g., International Journal of Computers for Mathematical Learning, becoming in 2011 Technology, Knowledge, and Learning: Learning Mathematics, Science, and the Arts in the Context of Digital Technologies, and the creation in 2015 of Digital Experiences in Mathematics Education. This trend has also witnessed an evolution of DTR with respect to mathematics education, from DTR occupying, 35 years ago, a distinctive part of the mathematics education territory to penetrating today this whole territory via multiple channels. Moreover, the pandemic period in which we are writing this article makes it even more obvious that, in mathematical education, rare are the didactical issues without a technological component.

Using the lens of DTR, we organized our analysis around three families of artefacts: dynamic geometry environments, calculators and computer algebra systems, and digital resources. We could have selected other entries. For instance, in the chapter on the French didactic tradition already mentioned [2], two mathematical domains were selected: (1) geometry through the particular case of didactic research on line symmetry and reflection and (2) algebra. The case study on algebra makes clear the importance of DTR in this area, with, for instance, the following projects:

- The Aplusix project initiated by Jean-François Nicaud [87], a computer scientist of the EIAH community, and continuously developed over three decades, already mentioned in the introduction;

- The Pépite project that emerged from the Grugeon doctoral thesis [88] and the multidimensional diagnostic tool of students' competences in elementary algebra developed in it, transformed into a digital diagnostic tool, Pépite [89], thanks to the collaboration between didacticians and computer scientists, continuously refined until today.

DTR on algebra teaching and learning offers complementary perspectives on the French didactic tradition, but the picture is globally coherent with the field we described. It shows a dynamic development of research with long-term projects and goals. It makes clear the role played by the three main theories of this tradition, as well as how DTR in this area contributes to their evolution. It also shows the importance of the long-term collaboration with the EIAH community in the development and progressive sophistication of digital artefacts incorporating results from didactic research, regarding first students and then also teachers. This is fully consistent with the evolution of the Cabri environment for instance.

Our choices were linked to our experiences in the French field of DTR and the role we played in some theoretical developments, especially the instrumental and the documentational approach to didactics. The resulting image is, thus, necessarily partial. We left aside important theorizations, the presentation of which would have required much longer developments. Let us quote, in particular, three examples:

- The cKc (conception, knowing, concept) framework, created by Balacheff [90], drawing out Vergnaud's frame of conceptualization, for an efficient design of teaching situations and learning environments, be they digital or not, with the additional ambition to build a bridge between research in mathematics education and research in educational technology;

- The modeling of the learner and their relationship with knowledge, developed in the frame of the ATD, throughout the notion of personal praxeology [91], evidencing the emergence of the cognitive subject inside the ATD;

- The "media-milieu dialectic" (dialectique media-milieu, in French), developed by Chevallard [92], for questioning the interactions, in the frame of a given institution, between existing media and the milieu $(\S 2)$, a medium being a system constituted for representing a part of the world to a given audience, including, but not restricted to, the digital environments.

Lastly, our visit to the French didactics tradition is made not only through technological lenses, but also through personal lenses. Each visit to a given territory should be considered as an introduction to this territory, to be completed afterward, and we hope that the references supporting this paper will allow the readers to organize their own tour. 
Author Contributions: Initial proposal M.A.; conceptualization M.A., L.T.; writing—original draft preparation, review and editing M.A., L.T. All authors have read and agreed to the published version of the manuscript.

Funding: This research received no external funding.

Institutional Review Board Statement: Not applicable.

Informed Consent Statement: Not applicable.

Data Availability Statement: Not applicable.

Acknowledgments: We thank Kenneth Ruthven for his thorough review of this article and for his wise advice, both on form and on substance.

Conflicts of Interest: The authors declare no conflict of interest.

\section{Short Biography of Authors}

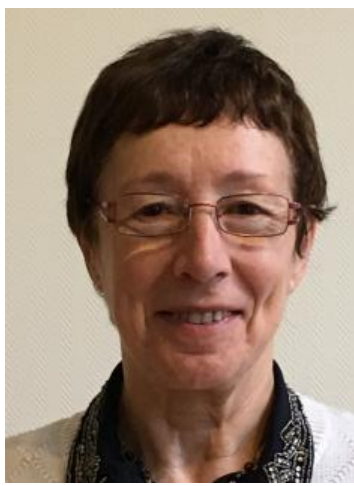

Michèle Artigue: Michèle Artigue is an Emeritus Professor at the Universite de Paris and an associate researcher of the Laboratoire de Didactique André Revuz. She gained a doctorate in mathematical logic (1972) and then a habilitation in the didactics of mathematics (1987) at the University Paris 7, where she spent most of her academic career. After her doctorate, she progressively engaged in didactic research. Her main research areas have been the didactics of calculus and analysis, as well as the teaching and learning of mathematics with technology. She has offered theoretical contributions on different themes concerning epistemology and didactics, didactical engineering, the instrumental approach, and the networking of theories. She has had and still has many editorial and scientific responsibilities. From 1998 to 2009, she was Vice President and then President of the International Commission on Mathematical Instruction (ICMI). She was awarded the ICMI Felix Klein Medal in 2013 and the Luis Santaló Medal in 2015.

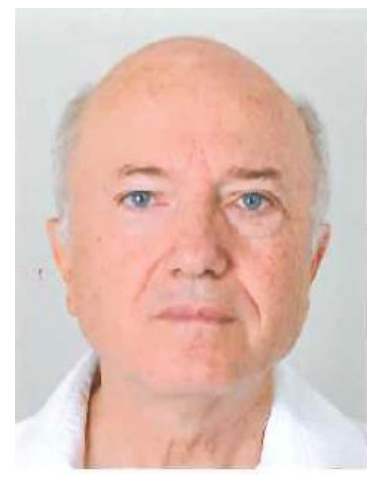

Luc Trouche: Luc Trouche is an Emeritus Professor at the Ecole Normale Supérieure de Lyon and an associate researcher of the S2HEP Laboratory. He gained a doctorate in didactics of mathematics (1996) at the University Montpellier 2 and then a habilitation (2003) at the University Paris 7. He spent his academic career first in Montpellier (Research Institute for the Teaching of Mathematics) and then in Lyon, at the French Institute of Education. His main research areas have been the teaching and learning of mathematics with technology and teacher professional development, seen particularly through their interactions with resources. He has offered theoretical contributions on different themes, mainly the instrumental approach and the documentational approach to didactics. From 2012 to 2016, he was President of the French Commission on Mathematical Instruction

\section{References}

1. Blum, W.; Artigue, M.; Mariotti, M.A.; Sträßer, R.; Van den Heuvel-Panhuizen, M. (Eds.) European Traditions in Didactics of Mathematics (ICME-13 Monograph); Springer: Cham, Switzerland, 2019.

2. Artigue, M.; Bosch, M.; Chaachoua, H.; Chellougui, F.; Chesnais, A.; Durand-Guerrier, V.; Knipping, C.; Maschietto, M.; RomoVázquez, A.; Trouche, L. The French didactics tradition in mathematics. In European Traditions in Didactics of Mathematics (ICME-13 Monograph); Blum, W., Artigue, M., Mariotti, M.A., Sträßer, R., Van den Heuvel-Panhuizen, M., Eds.; Springer: Cham, Switzerland, 2019; pp. 11-55.

3. Artigue, M. (Ed.) La Tradition Didactique Française au-delà des Frontières. Exemples de Collaborations avec l'Afrique, l'Amérique Latine et l'Asie; Commission Française pour l'Enseignement des Mathématiques: Lyon, France, 2016. Available online: http: / / www.cfem.asso.fr/cfem/Collaborationsdidactiquesfrancaises.pdf (accessed on 13 March 2021).

4. Trouche, L. From Artifact to Instrument: Mathematics Teaching Mediated by Symbolic Calculators. Interact. Comput. 2003, 15, 783-800. [CrossRef] 
5. Trouche, L.; Gueudet, G.; Pepin, B. Documentational approach to didactics. In Encyclopedia of Mathematics Education, 2nd ed.; Lerman, S., Ed.; Springer: Cham: Switzerland, 2020; pp. 307-313. [CrossRef]

6. Balacheff, N.; Vivet, M. (Eds.) Didactique et Intelligence Artificielle; La Pensée Sauvage Éditions: Grenoble, France, 1994.

7. Vergnaud, G.; Brousseau, G.; Hulin, M. Didactique des Acquisitions des Connaissances Scientifiques. Actes du Colloque de Sèvres. Mai 1987; La Pensée Sauvage Éditions: Grenoble, France, 1988.

8. Brousseau, G. Theory of Didactical Situations in Mathematics; Kluwer Academic Publishers: Dordrecht, The Netherlands, 1997.

9. Vergnaud, G. The theory of conceptual fields. Hum. Dev. 2009, 52, 83-94. [CrossRef]

10. Chevallard, Y. Introducing the Anthropological Theory of the Didactic: An attempt at a principled approach. Hiroshima J. Math. Educ. 2019, 12, 1-44.

11. Robert, A.; Rogalski, J. Le système complexe et cohérent des pratiques des enseignants de mathématiques: Une double approche. Rev. Can. L'enseign. Sci. Math. Technol. 2002, 2, 505-528. [CrossRef]

12. Gispert, H. Mathematics education in France, 1900-1980. In Handbook on the History of Mathematics Education; Springer: Cham, Switzerland, 2014; pp. 229-240.

13. Trouche, L. Didactics of Mathematics: Concepts, Roots, Interactions and Dynamics from France. In Tools and Mathematics, Instruments for Learning; Monaghan, J., Trouche, L., Borwein, J.M., Eds.; Springer: Cham, Switzerland, 2016; pp. 219-256.

14. Artigue, M. Perspectives on Design Research: The Case of Didactical Engineering. In Approaches to Qualitative Research in Mathematics Education; Bikner-Ahsbahs, A., Knipping, C., Presmeg, N., Eds.; Springer: New York, NY, USA, 2014 ; pp. 467-496.

15. Chevallard, Y. La Transposition Didactique; La Pensée Sauvage éditions: Grenoble, France, 1985.

16. Brousseau, G.; Brousseau, N.; Warfield, V. Teaching Fractions through Situations: A fundamental Experiment; Springer: New York, NY, USA, 2014.

17. Laborde, J.M. Technology-Enhanced Teaching/Learning at a New Level with Dynamic Mathematics as Implemented in the New Cabri. In Digital Curricula in School Mathematics. Part I: Creating Digital Curriculum; Beates, M., Usiskin, Z., Eds.; The University of Chicago: Chicago, CH, USA, 2016; pp. 53-74.

18. Laborde, C.; Capponi, B. Cabri-géomètre constituant d'un milieu pour l'apprentissage de la notion de figure géométrique. Rech. Didact. Math. 1994, 14, 165-210.

19. Parzysz, B. Knowing vs Seeing. Problems of the plane representation of space geometry figures. Educ. Stud. Math. 1988, 19, 79-92. [CrossRef]

20. Laborde, C. Integration of geometry in the design of geometry tasks with Cabri-geometry. Int. J. Comput. Math. Learn. 2001, 6, 283-317. [CrossRef]

21. Falcade, R.; Laborde, C.; Mariotti, M.A. Approaching functions: Cabri tools as instruments of semiotic mediation. Educ. Stud. Math. 2007, 66, 317-333. [CrossRef]

22. Healy, L. Identifying and explaining geometrical relationship: Interactions with robust and soft Cabri constructions. In Proceedings of the 24th Conference of the International Group for the Psychology of Mathematics Education, Hiroshima, Japan, 23-27 July 2000; Tadao Nakahara, Masataka Koyama: Hiroshima, Japan, 2000; Volume 1, pp. 103-117.

23. Arzarello, F.; Gallino, G.; Micheletti, C.; Olivero, F.; Paola, D.; Robutti, O. Dragging in Cabri and modalities of transition from conjectures to proofs in geometry. In Proceedings of the 22nd Conference of the International Group for the Psychology of Mathematics Education, Stellenbuch, South Africa, 12-17 July 1998; Volume 2, pp. 32-39.

24. Laborde, C.; Assude, T.; Grugeon, B.; Soury-Lavergne, S. Study of a teacher professional problem: How to take into account the instrumental dimension when using Cabri-geometry? In Proceedings of the Seventeenth ICMI Study Conference "Technology Revisited", Hanoi, Vietnam, 3-8 December 2006; Hoyles, C., Lagrange, J.-B., Son, L.-H., Sinclair, N., Eds.; Hanoi Institute of Technology: Hanoi, Vietnam, 2006; pp. 317-325.

25. Guin, D.; Trouche, L. The Complex Process of Converting Tools into Mathematical Instruments. The Case of Calculators. Int. J. Comput. Math. Learn. 1998, 3, 195-227. [CrossRef]

26. Artigue, M. Le logiciel DERIVE comme révélateur de phénomènes didactiques liés à l'utilisation d'environnements informatiques pour l'apprentissage. Educ. Stud. Math. 1997, 33, 133-169. [CrossRef]

27. Hirlimann, A. (Ed.) Enseignement des Mathématiques et Logiciels de Calcul Formel; Ministère de l'Education Nationale, DITEN B2: Paris, France, 1994.

28. Guin, D.; Trouche, L. Seeing is Reality: How Graphic Calculators May Influence the Conceptualization of Limits. In Proceedings of the PME 20, Valencia, Spain, 8-12 July 1996; Puig, L., Gutiérrez, A., Eds.; Universitat de València: València, Spain, 1996; Volume 4, pp. 323-330.

29. Balacheff, N. Didactique et intelligence artificielle. Rech. Didact. Math. 1994, 14, 9-42.

30. Rabardel, P. Les Hommes et les Technologies. Approche Cognitive des Instruments Contemporains; Armand Colin: Paris, France, 1995.

31. Verillon, P.; Rabardel, P. Cognition and artifact: A contribution to the study of thought in relation to instrument activity. Eur. J. Psychol. Educ. 1995, 9, 77-101. [CrossRef]

32. Artigue, L. Rapports entre dimensions technique et conceptuelle dans l'activité mathématique avec des systèmes de mathématiques symboliques. In Actes de l'Université d'été " Des Outils Informatiques dans la Classe aux Calculatrices Symboliques et Géométriques: Quelles Perspectives pour L'enseignement des Mathématiques; IREM: Rennes, France, 1997; pp. 19-40. 
33. Trouche, L. A la recherche d'une méthode d'étude de l'action instrumentée. In Actes de l'Université d'été «Des Outils Informatiques dans la Classe aux Calculatrices Symboliques et Géométriques: Quelles Perspectives pour L'enseignement des Mathématiques»; IREM: Rennes, France, 1997; pp. 113-148.

34. Defouad, B. Étude de Genèses Instrumentales Liées à L'utilisation D'une Calculatrice Symbolique en Classe de Première S. Ph.D. Thesis, Paris 7 University, Paris, France, 2000.

35. Trouche, L. A Propos de L'apprentissage des Limites de Fonctions, Etude des Rapports Entre Processus D'instrumentation et Processus de Conceptualisation. Ph.D. Thesis, Montpellier 2 University, Montpellier, France, 1996.

36. Maschietto, M. L'enseignement de L'analyse au Lycée: Les Débuts du jeu Global/Local Dans L'environnement de Calculatrices. Ph.D. Thesis, Paris 7 University, Paris, France, 2002.

37. Guin, D.; Trouche, L. Analyser l'usage didactique d'un EIAH en mathématiques, une tâche nécessairement complexe. Sci. Tech. Educ. 2001, 8, 61-74. [CrossRef]

38. Restrepo, A. Genèse Instrumentale du Déplacement en Géométrie Dynamique Chez des Elèves de 6ème. Ph.D. Thesis, Grenoble 1 University, Grenoble, France, 2008.

39. Haspekian, M. Intégration D'outils Informatiques dans L'enseignement des Mathématiques: Étude du cas des Tableurs. Ph.D. Thesis, Paris 7 University, Paris, France, 2005.

40. Rabardel, P. Éléments pour une approche instrumentale en didactique des mathématiques. In Actes de L'école d'été de Didactique des Mathématiques; Bailleul, M., Ed.; ARDM \& IUFM: Caen, France, 2000; pp. 202-213.

41. Lagrange, J.-B. Les instruments de calcul formel. In Actes de la Dixième Université d'été de Didactique des Mathématiques; Bailleul, M., Ed.; IUFM \& ARDM: Caen, France, 1999; pp. 235-244.

42. Laborde, C. L'activité instrumentée par des logiciels de géométrie dynamique. In Actes de la Dixième Université d'été de Didactique des Mathématiques; Bailleul, M., Ed.; IUFM \& ARDM: Caen, France, 1999; pp. 214-234.

43. Guin, D. (Ed.) Calculatrices Symboliques et Géométriques dans L'enseignement des Mathématiques. Actes du Colloque Francophone Européen de La Grande-Motte; IREM, Université Montpellier 2: Montpellier, France, 1998.

44. Artigue, M. Learning mathematics in a CAS environment: The genesis of a reflection about instrumentation and the dialectics between technical and conceptual work. Int. J. Comput. Math. Learn. 2002, 7, 245-274. [CrossRef]

45. Guin, D.; Ruthven, K.; Trouche, L. (Eds.) The Didactical Challenge of Symbolic Calculators: Turning a Computational Device into a Mathematical Instrument; Springer: New York, NY, USA, 2005.

46. Hoyles, C.; Lagrange, J.-B. Mathematics Education and Technology-Rethinking the Terrain. The 17th ICMI Study; Springer: New York, NY, USA, 2010.

47. Lagrange, J.-B.; Artigue, M.; Laborde, C.; Trouche, L. Technology and mathematics education: A multidimensional study of the evolution of research and innovation. In Second International Handbook of Mathematics Education; Bishop, A.J., Clements, M.A., Keitel, C., Kilpatrick, J., Leung, F.K.S., Eds.; Kluwer Academic Publishers: Dordrecht, The Netherlands, 2003 ; pp. $239-271$.

48. Chevallard, Y. Familière et problématique, la figure du professeur. Rech. Didact. Math. 1997, 17, 17-54.

49. Margolinas, C. Situations, milieux, connaissances: Analyse de l'activité du professeur. In Actes de la 11ème Ecole d'Eté de Didactique des Mathématiques; Dorier, J.-L., Artaud, M., Artigue, M., Berthelot, R., Floris, R., Eds.; La Pensée Sauvage Éditions: Grenoble, France, 2002; pp. 141-156.

50. Trouche, L. Managing the complexity of human/machine interactions in computerized learning environments: Guiding students' command process through instrumental orchestrations. Int. J. Comput. Math. Learn. 2004, 9, 281-307. [CrossRef]

51. Trouche, L.; Drijvers, P. Handheld technology for mathematics education, flashback to the future. ZDM Int. J. Math. Educ. 2010, 42, 667-681. [CrossRef]

52. Haspekian, M. The co-construction of a mathematical and a didactical instrument. In Proceedings of the CERME 7, Rzeszów, Poland, 9-13 February 2011; Pytak, M., Swoboda, E., Rowland, T., Eds.; University of Rzeszów and ERME: Rzeszów, Poland, 2011; pp. 2298-2307.

53. Abboud, M.; Vandebrouck, F. Geneses of technology uses: A theoretical model to study the development of teachers' practices in technology environments. In Proceedings of the CERME 8, Antalya, Turkey, 6-10 February 2013; Ubuz, B., Haser, C., Mariotti, M.A., Eds.; Université de Sherbrooke: Sherbrooke, QC, Canada, 2013; pp. 2504-2513.

54. Artigue, M.; Groupe TICE IREM de Paris. Lutilisation de ressources en ligne pour lenseignement des mathématiques au lycée: Du suivi d'une expérimentation régionale à un objet de recherche. In Actes du Colloque EMF 2006. L'enseignement des Mathématiques Face aux Défis de L'école et des Communautés; Bednarz, N., Mary, C., Eds.; Université de Sherbrooke: Sherbrooke, QC, Canada, 2008; Thème 5; pp. 1-11.

55. Guin, D.; Trouche, L. Distance training, a key mode to support teachers in the integration of ICT? In Proceedings of the Fourth European Conference on Research on Mathematics Education, Sant Feliu de Guíxols, Spain, 17-21 February 2005; Bosch, M., Ed.; FUNDEMI IQS, Universitat Ramon LLull: Barcelona, Spain, 2005; pp. 1020-1029.

56. Lagrange, J.-B.; Abboud Blanchard, M.; Loisy, C.; Vandebrouck, F. Rapport final de la Recherche Genèse d'usages Professionnels des Technologies par les Enseignants. 2009. Available online: http: / / gupten.free.fr/ (accessed on 13 March 2021).

57. Sokhna, M. Formation à Distance des Professeurs de Mathématiques au Sénégal, Genèse Instrumentale de Ressources Pédagogiques. Ph.D. Thesis, Montpellier 2 University, Montpellier, France, 2006.

58. Lagrange, J.-B. Complex calculators in the classroom: Theoretical and practical reflections on teaching pre-calculus. Int. J. Comput. Math. Learn. 1999, 4, 51-81. [CrossRef] 
59. Monaghan, J. Computer algebra, instrumentation and the anthropological approach. Int. J. Technol. Math. Educ. 2007, 14, 63-71.

60. Gueudet, G.; Trouche, L. Conceptions et usages de ressources pour et par les professeurs, développement associatif et développement professionnel. Doss. L'ingénierie Educ. 2009, 65, 76-80.

61. Gueudet, G. Studying teachers' documentation work. In The 'Resource' Approach to Mathematics Education; Trouche, L., Gueudet, G., Pepin, B., Eds.; Springer: Cham, Switzerland, 2019; pp. 17-42.

62. Adler, J. Conceptualising resources as a theme for teacher education. J. Math. Teach. Educ. 2000, 3, 205-224. [CrossRef]

63. Baron, M.; Guin, D.; Trouche, L. (Eds.) Environnements Informatisés et Ressources Numériques pour l'apprentissage: Conception et Usages, Regards Croisés; Hermès: Paris, France, 2007.

64. Pédauque, R.T. Le Document à la Lumière du Numérique; C \& F éditions: Caen, France, 2006.

65. Folcher, V. Conception pour l'usage, conception dans l'usage: Quelles ressources pour quelles activités? In Nouvelles Perspectives en Didactique des Mathématiques; Bloch, I., Conne, F., Eds.; La Pensée Sauvage: Grenoble, France, 2009; pp. 95-108.

66. Gueudet, G.; Trouche, L. Vers de nouveaux systèmes documentaires des professeurs de mathématiques. In Nouvelles Perspectives en Didactique des Mathématiques; Bloch, I., Conne, F., Eds.; La Pensée Sauvage éditions: Grenoble, France, 2009 ; pp. 109-133.

67. Margolinas, C.; Wozniak, F. Place des documents dans l'élaboration d'un enseignement de mathématiques à l'école primaire. In Nouvelles Perspectives en Didactique des Mathématiques; Bloch, I., Conne, F., Eds.; La Pensée Sauvage éditions: Grenoble, France, 2009; pp. 135-146.

68. Gueudet, G.; Trouche, L. Teachers' work with resources: Documentation geneses and professional geneses. In From Text to 'Lived' Resources: Mathematics Curriculum Materials and Teacher Development; Gueudet, G., Pepin, B., Trouche, L., Eds.; Springer: New York, NY, USA, 2012; pp. 23-41.

69. Gueudet, G.; Buteau, C.; Mesa, V.; Misfeldt, M. Instrumental and documentational approaches: From technology use to documentation systems in university mathematics education. Res. Math. Educ. 2014, 16, 139-155. [CrossRef]

70. Gueudet, G.; Trouche, L. Étudier les interactions professeurs-ressources: Questions de méthode. Educ. Didact. 2021. to appear.

71. Sabra, H. L'étude des rapports entre documentations individuelle et collective: Incidents, connaissances et ressources mathématiques. Rech. Didact. Math. 2016, 36, 49-95.

72. Hammoud, R. Le Travail Collectif des Professeurs en Chimie Comme Levier pour la Mise en Euvre de Démarches D'investigation et le Développement des Connaissances Professionnelles. Contribution au développement de L'approche Documentaire du Didactique. Ph.D. Thesis, Lyon 1 University and Lebanese University, Villeurbanne, France, 2012.

73. Rocha, K. Une étude des Effets du Travail Documentaire et Collectif sur le Développement Professionnel des Enseignants de Mathématiques: Apport des Concepts D'expérience et de Trajectoire Documentaires. Ph.D. Thesis, ENS de Lyon, Lyon, France, 2019.

74. Gueudet, G.; Trouche, L. Du travail documentaire des enseignants: Genèses, collectifs, communautés. Le cas des mathématiques. Educ. Didact. 2008, 2, 7-33. [CrossRef]

75. Pepin, B.; Gueudet, G.; Trouche, L. Re-sourcing teachers' work and interactions: A collective perspective on resources, their use and transformation. ZDM Math. Educ. 2013, 45, 929-944. [CrossRef]

76. Besnier, S. Le Travail Documentaire des Professeurs à L'épreuve des Ressources Technologiques. Le cas de L'enseignement du Nombre à l'école Maternelle. Ph.D. Thesis, Brittany University, Rennes, France, 2016.

77. Pepin, B.; Xu, B.; Trouche, L.; Wang, C. Developing a deeper understanding of mathematics teaching expertise: Chinese mathematics teachers' resource systems as windows into their work and expertise. Educ. Stud. Math. 2017, 94, 257-274. [CrossRef]

78. Ruthven, K. The Construct of 'Resource System' as an Analytic Tool in Understanding the Work of Teaching. In The 'Ressource' Approach to Mathematics Education; Trouche, L., Gueudet, G., Pepin, B., Eds.; Springer: Cham, Switzerland, 2019 ; pp. 43-59.

79. Fan, L.; Trouche, L.; Qi, C.; Rezat, S.; Visnovska, J. (Eds.) Research on Mathematics Textbooks and Teachers' Resources: Advances and issues; Springer: Cham, Switzerland, 2018.

80. Remillard, J.T. Examining key concepts in research on teachers' use of mathematics curricula. Rev. Educ. Res. 2005, 75, 211-246. [CrossRef]

81. Gueudet, G.; Trouche, L. (Eds.) Ressources Vives, la Documentation des Professeurs en Mathématiques; PUR \& INRP: Rennes, France, 2010.

82. Gueudet, G.; Pepin, B.; Trouche, L. (Eds.) From Text to 'Lived' Resources: Mathematics Curriculum Materials and Teacher Development; Springer: New York, NY, USA, 2012.

83. Gitirana, V.; Miyakawa, T.; Rafalska, M.; Soury-Lavergne, S.; Trouche, L. (Eds.) Proceedings of the Re(s)sources 2018 International Conference. Available online: https:/ / hal.archives-ouvertes.fr/hal-01764563v3/document (accessed on 13 March 2021).

84. Trouche, L. Evidencing missing resources of the documentational approach to didactics. Towards ten programs of research/ development for enriching this approach. In The 'Ressource' Approach to Mathematics Education; Trouche, L., Gueudet, G., Pepin, B., Eds.; Springer: Cham, Switzerland, 2019; pp. 447-489.

85. Trouche, L.; Adler, J.; Remillard, J. (Eds.) Conceptualizing teachers' interactions with resources in crossing languages and cultures. Special issue. In ZDM Math. Educ.; to be published in 2023.

86. Cornu, B.; Ralston, A. The Influence of Computers and Informatics on Mathematics and its Teaching, 2nd ed.; UNESCO: Paris, France, 1992.

87. Bouhineau, D.; Nicaud, J.F. APLUSIX, un EIAH de l'algèbre. In Environnements Informatiques et Apprentissage Humain; Grandbastien, M., Labat, J.-M., Eds.; Hermès-Lavoisier: Paris, France, 2006; pp. 333-350.

88. Grugeon-Allys, B. Etude des Rapports Institutionnels et des Rapports Personnels des Elèves à L'algèbre Elémentaire dans la Transition Entre deux Cycles D'enseignement: BEP et Première G. Ph.D. Thesis, Paris 7 University, Paris, France, 1995. 
89. Grugeon-Allys, B.; Chenevotot-Quentin, F.; Pilet, J.; Prévit, D. Online automated assessment and student learning: The Pepite project in elementary algebra. In Uses of Technology in K-12 Mathematics Education: Tools, Topics and Trends; Ball, L., Drijvers, P., Ladel, S., Siller, H.-S., Tabach, M., Vale, C., Eds.; Springer: New York, NY, USA, 2018; pp. 245-266.

90. Balacheff, N. A knowledge model drawn from an understanding of students understanding. Didactical principles and model specifications. In Baghera Assessment Project, Designing an Hybrid and Emergent Educational Society; Soury-Lavergne, S., Ed.; Cahier Leibniz: Grenoble, France, 2003; pp. 3-22.

91. Crozet, M.-C.; Chaachoua, H. Une réponse à la prise en compte de l'apprenant dans la TAD: La praxéologie personnelle. Rech. Didact. Math. 2016, 36, 161-196.

92. Chevallard, Y. Un concept en émergence: La dialectique des médias et des milieux. In Actes du Séminaire National de Didactique des Mathématiques; Gueudet, G., Matheron, Y., Eds.; ARDM et IREM: Paris, France, 2007; pp. 344-366. 